Atract

\title{
Feasibility of Using Biomass Fly Ash in Cementitious Materials ${ }^{+}$
}

\author{
Jonathan Page ${ }^{1, *}$, Laurent Libessart ${ }^{1}$, Chafika Djelal ${ }^{1}$, Maurice Gonon ${ }^{2}$ and Issam Laiymani ${ }^{1}$ \\ 1 Laboratoire de Génie Civil et géo-Environnement (LGCgE), Artois University, EA 4515, 62408 Béthune, \\ France; laurent.libessart@univ-artois.fr (L.L.); chafika.dantec@univ-artois.fr (C.D.); \\ issam.laiymani@univ-artois.fr (I.L.) \\ 2 Materials Institute, University of Mons-Hainaut, 7000 Mons, Belgium; mauricefrancois.gonon@umons.ac.be \\ * Correspondence: jonathan.page@univ-artois.fr \\ + Presented at the 1st International Conference on Smart Materials for Sustainable Construction-SMASCO \\ 2019, Luleå, Sweden, 10-12 December 2019.
}

Published: 18 November 2019

\begin{abstract}
In recent years, numerous studies focused on the development of sustainable cementbased binders through the use of supplementary cementitious materials such slag, fly ash, metakaolin, silica fume, pozzolan, etc. The use of wood biomass for power generation is increasingly common which lead to an important amount of waste produced in the combustion process such as fly ash, which must be transported to landfills for deposition, or used as sludge in farming. Depending on their chemical and physical characteristics, wood biomass fly ashes could be reuse in blended cements as supplementary cementitious material. Different sources of biomass fly ashes have been selected to evaluate their potential for use as a cement replacement. Their chemical and mineralogical compositions, as well as their morphology were first evaluated via X-ray and laser diffraction (XRD), inductively coupled plasma (ICP) and scanning electron microscopy (SEM coupled with energy-dispersive X-ray spectroscopy (EDX). Fly ashes showed variable physicochemical characteristics but some present interesting compositions for the intended use. One fly ash present a high content of $\mathrm{CaO}$ and minors of $\mathrm{SiO}_{2}$ and $\mathrm{Al}_{2} \mathrm{O}_{3}$. The chemical composition does not allow to categorize this fly ash as a pozzolan material but it may have a latent hydraulic behaviour, which could be interesting as cement substitution. This fly ash has been incorporated into a cement paste by progressive replacement of Portland cement (from 0 to $70 \%$ ). It has been observed that biomass fly ash has a higher water demand compared to Portland cement. This additional water demand was evaluated by the Vicat consistency test and by an evaporometry method. The setting time and kinetic hydration of the biomass fly ash pastes were also assessed with the standardized Vicat test and by isothermal calorimetry.
\end{abstract}

Keywords: feasibility; cementitious materials; eco-friendly binder; chemical composition; absorption

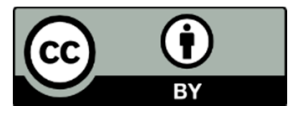

(C) 2019 by the authors. Licensee MDPI, Basel, Switzerland. This article is an open access article distributed under the terms and conditions of the Creative Commons Attribution (CC BY) license (http://creativecommons.org/licenses/by/4.0/). 